\title{
El taller de Miedes (Zaragoza, 1776 ca. 1835) y su relación con la Real Sociedad Económica Aragonesa de Amigos del País
}

\author{
Alejandrina Aguas COMPAIRED y Ana BALLESTERo PASCUAL \\ (Universidad de Zaragoza)
}

Resumen

Este artículo narra la historia del taller que fundó Blas Miedes en Zaragoza y la relación que todos sus miembros tuvieron con instituciones tan importantes como la Real Sociedad Económica Aragonesa de Amigos del País. Además se ha logrado dar nombre y apellidos a dos mujeres impresoras que dirigieron el taller y que solo eran conocidas como «viudas de» otorgándoles la entidad que se merecen.

Palabras clave: Miedes; Imprenta; Real Sociedad Económica Aragonesa de Amigos del País; Zaragoza; s. XVIII - XIX; Miedes, Blas; Lloscos, Bruna; Miedes, Mariano; Frasinete, Braulia; Viuda de Blas Miedes; Viuda de Mariano Miedes.

\section{The Miedes Workshop (Zaragoza 1776 c. 1835) and its Relationship with the Real Sociedad Económica Aragonesa de Amigos del País}

Abstract

This article traces the history of the workshop that Blas Miedes founded in Zaragoza and the relationship that all its members had with such important institutions as the Real Sociedad Económica Aragonesa de Amigos 
el País. In addition, two women printers who managed the workshop and who were known only as «the widows of such and such» have been properly identified.

Keywords: Miedes; Printing; Real Sociedad Económica Aragonesa de Amigos del País: Zaragoza; XVIII XIX centuries; Miedes, Blas; Lloscos, Bruna; Miedes, Mariano; Frasinete, Braulia; The Wdow of Blas Miedes; The Widow of Mariano Miedes.

\section{Contexto cultural ${ }^{1}$}

En la segunda mitad del siglo XVIII, Zaragoza empezó a recuperarse de la recesión económica, política y social que sufrió a principio de este periodo debido, sobre todo, a la Guerra de Sucesión. Poco a poco la ciudad comenzó a ser un referente en cuanto a comercio, cultura y prosperidad urbana al aumentar la población y convertirse en un centro burocrático de relevancia.

Esta recuperación se debió a dos hitos importantes: por una parte la construcción del Canal Imperial de Aragón impulsada por Ramón de Pignatelli y por otra, la fundación en 1776 de la Real Sociedad Económica Aragonesa de Amigos del País, ${ }^{2}$ institución que a día de hoy todavía sigue en activo.

A estos dos factores se le une un tercero, la legislación de los años 60 aplicada por el Borbón Carlos III quien trató de dar un empuje al mundo del libro al promulgar una serie de leyes que favorecieron su fabricación y comercio.

Esta prosperidad cultural y económica se prolongó hasta comienzos del siglo XIX, momento en el cual la ciudad sufrió otro gran revés con la Guerra de la Independencia y los conocidos Sitios de Zaragoza. Las consecuencias fueron devastadoras al quedar la urbe prácticamente en ruinas y con un número mermado de población — de sus 50.000 habitantes pasó a tener 12.000 - , por lo que los zaragozanos tuvieron que reponerse de grandes pérdidas materiales, económicas y sociales.

\footnotetext{
1 Para la creación de este artículo hemos partido de una obra básica como es el libro de Manuel JimÉNEZ CATALÁN, Ensayo de una tipografía zaragozana del siglo XVIII, Zaragoza, La Academia, 1929 y del Catálogo Colectivo del PAtrimonio Bibliográfico. Estas dos herramientas nos han facilitado acotar las etapas laborales de los miembros que formaron el taller, así como estudiar sus obras impresas. Además, hemos consultado otra serie de archivos como el del COLEgio Notarial de Aragón de ZARAgOZA (ANZ) donde hemos encontrado documentación relacionada con los Miedes, el ARCHIVO Diocesano de Zaragoza (ADZ) y el ArChivo CAPitular Del Pilar (ACP) donde se guardan los libros parroquiales de esta ciudad y por tanto, muy útiles para saber las fechas de nacimientos, muertes y matrimonios y finalmente, el ARCHIVO DE LA REAL SOCIEDAD ECONÓMICA ARAgONESA DE Amigos Del PAís (ARSEZ) puesto que las sucesivas generaciones de esta familia fueron nombrados impresores de esta institución.

${ }^{2}$ En adelante esta institución aparecerá mencionada como «Real Sociedad».
} 
En este contexto nació el taller de la familia Miedes, bajo la dirección del cabeza de familia Blas, y finalizó con la segunda esposa de su hijo Mariano. A pesar de ser uno de los grandes establecimientos de su época, ha sido poco estudiado, ya que este siglo es uno de los más ignorados en el mundo de la imprenta, la industria y el comercio del libro aragonés, por lo que con este artículo pretendemos exponer la trayectoria laboral de todos los miembros que lo compusieron.

\section{Blas Miedes (1776 1786)}

Blas Miedes era natural de Alfambra (Teruel), hijo de Blas Miedes y de María Ibáñez, aunque toda su andadura profesional transcurrió en la ciudad de Zaragoza, donde residió hasta el final de sus días junto a la que fue su esposa, Bruna Lloscos.

Blas y Bruna contrajeron nupcias el 26 de octubre de $1760 .{ }^{3}$ Bruna era oriunda de Zaragoza, hija de Joseph Lloscos y de Vicenta Alicante. El matrimonio tuvo siete hijos ${ }^{4}$ — Rita, Fausto, María, Vicenta, Polonia, Mariano Gabriel y Mariano Ángel- de los que solamente cuatro sobrevivieron a sus padres: María, Vicenta, Mariano y Ángel (Fig. 15).

Poco se sabe sobre los comienzos de Blas como impresor, lo que sí hemos averiguado es que en 1776 ya es citado en una escritura de compraventa como «de oficio impresor»..$^{5}$ Gracias a este texto conocemos que Francisco Iñiguez Bardají le vendió un terreno sito en la calle Sepulcro número 126 (Fig. 14), lugar en el que Miedes asentó su residencia y su taller, tal y como aparece en el pie de imprenta de algunos de sus libros. ${ }^{6}$ (Fig. 1)

Tres años después, en 1779 Blas obtuvo un poder por parte del Cabildo Metropolitano de San Salvador para recaudar dinero en la zona de Vizcaya para la fábrica de la Basílica del Pilar. Con este trabajo consiguió una fuente extra de financiación para poder invertir en su negocio y así, poder darle el impulso necesario para adquirir el prestigio que le asegurara su sustento económico. ${ }^{7}$

Blas Miedes no cejó en su intento de convertir su taller en uno de los mejores de Zaragoza, por ello el 26 de enero de 1781 solicitó convertirse en

\footnotetext{
3 ADZ. Libro sacramental de la parroquia de La Magdalena, 1746 - 1764, tomo 8, p. 1.128.

${ }^{4}$ ADZ. Libros sacramentales de la parroquia de La Magdalena, 1746 - 1786, tomos 8, 9 y 10.

5 ANZ. Escritura de compraventa, Protocolo de Francisco Antonio Torrijos, 1776, signatura 4974, ff. 24 - 25.

${ }^{6}$ Anotación que aparece en la portada del libro: Pedro José LóPEZ, Villancicos, que se han de cantar en la Iglesia Parroquial de el Señor San Pablo de la Imperial ciudad de Zaragoza, en la celebridad... de el Nacimiento de Nuestro Señor Jesu-Christo, en Zaragoza, en la imprenta de Blas Miedes, [s. a.].

7 ANZ. Protocolo de Manuel Lucas Leiza, 1779, signatura 4928, ff. 56 - 57v.
} 
impresor de la Real Sociedad Económica Aragonesa de Amigos del País, para lo que presentó un memorial alegando que ya había realizado trabajos previos para esta institución y que:

Poseía los signos y quebrados que se habían usado para la impresión de las matemáticas que el Señor Director Segundo hizo traher de Barcelona y que en el dia existen en poder de este interesado, como tanbien el sello o armas de la Sociedad de Vox, que el Señor Goycochea hizo traher de Valencia. ${ }^{8}$

Por fin, el 9 de marzo de $1781^{9}$ Blas consiguió ser nombrado impresor de dicha sociedad ganando así a otros dos colegas suyos, Antonio Heras y Esteban de Ara, que también habían solicitado tan preciado puesto.

Con esta institución Blas Miedes imprimió un gran número de obras como los Rudimentos de aritmetica, algebra y dinamica de Jaime Conde ${ }^{10}$ o los tomos del Ensayo histórico apologético de la literatura española contra las opiniones preocupadas de algunos escritores modernos italianos de la literatura antigua y moderna de Francisco Javier Lampillas, traducido por Josefa de Amar y Borbón. ${ }^{11}$

Pero no solo imprimió para la Real Sociedad, sino que también realizó otros encargos, sobre todo de carácter religioso, para el Arzobispo de Zaragoza Agustín de Lezo y Palomeque gran reformador y generoso mecenas de la época. Así mismo son famosos sus impresos de carácter más «populan» como villancicos, instrucciones para educar a la población, etc.

En 1781 Blas y Bruna vendieron el terreno de la calle Sepulcro ${ }^{12}$ para trasladarse a la calle Gavín no 163 (Fig. 14) tal y como demuestran los libros de matrícula de la parroquia de La Magdalena. ${ }^{13}$

Estos mismos documentos revelan que en 1782, Francisco Magallón ${ }^{14}$ residía en el hogar de los Miedes, quizás como aprendiz o ayudante en la imprenta familiar, pues desconocemos con exactitud el cargo que ocupó. Posteriormente, Francisco contrajo nupcias con Vicenta Miedes, hija de Blas y

\footnotetext{
8 ARSEZ. Acta del 21/01/1781, tomo 7.

9 ARSEZ. Acta del 9/03/1781, tomo 7.

${ }^{10}$ Jaime CONDE, Rudimentos de arismetica, para facilitar la enseñanza en la Escuela Patriotica de la Real Sociedad Aragonesa de Amigos del Pais, En Zaragoza, por Blas Miedes..., 1781; Rudimentos de algebra, para facilitar la enseñanza en la Escuela Patriotica de la Real Sociedad Aragonesa de Amigos del Pais, En Zaragoza, por Blas Miedes..., 1782; Rudimentos de dinamica, para facilitar la enseñanza en la Escuela Patriotica de la Real Sociedad Aragonesa de Amigos del Pais, En Zaragoza, por Blas Miedes..., 1782.

11 Francisco Javier LAMPILLAS, Ensayo historico-apologético de la literatura española contra las opiniones preocupadas de algunos escritores modernos italianos, En Zaragoza, en la oficina de Blas Miedes ..., 1782.

12 ANZ. Protocolo de Francisco Antonio Torrijos, 1781, signatura 4975, ff. 38v - 39.

${ }^{13}$ ADZ. Libro de matrícula de la parroquia de La Magdalena, 1781.

${ }^{14}$ ADZ. Libro de matrícula de la parroquia de La Magdalena, 1783.
}

Titivillus, ISSN 2387-0915, ISSN-e 2603-9966, 4 (2018), pp. 63-79 
Bruna, y estableció su propio taller, consiguiendo ser una de las grandes figuras artísticas de este siglo.

El 14 de febrero de 1783 Blas Miedes logró dar otro gran paso en su carrera laboral ya que la Real Sociedad le concedió permiso para colocar sobre el dintel de acceso a su taller el nombre de esta institución. Con esta medida Blas pretendía alcanzar un mayor reconocimiento entre el público y a la vez, atraer a posibles clientes.

Viose un memorial de Blas Miedes, impresor de este Real Cuerpo, suplicando se le permita colocar sobre la puerta de su casa y oficina el quadro que hizo presente, en que esta pintada decentemente la empresa de la Sociedad, cuia licencia se le concedio durante la voluntad de esta. ${ }^{15}$

El 10 de noviembre de 1786 Blas falleció en su domicilio de la calle Gavín a la edad de 46 años, ${ }^{16}$ no sin antes otorgar testamento a favor de su mujer Bruna Lloscos y sus cuatro hijos ${ }^{17}$ (Fig. 15).

Como muchos de los impresores de su época, la familia Miedes empleó las marcas tipográficas para identificar su trabajo y a la vez como símbolo de calidad de su taller. Imprimieron en sus trabajos diferentes marcas, ${ }^{18}$ pero una constante en dichos grabados fue el uso de un blasón construido con una composición de su nombre enmarcado por motivos vegetales. Tanto la onomástica como el fondo ornamental variaron a lo largo de los años, unas veces emplearon su nombre completo y otras, un monograma con sus iníciales.

La primera marca que utilizó Blas Miedes fue en 1784 y representa su nombre completo rodeado por un gran grabado decorativo. Destaca en ella la utilización de una doble flecha como elemento rubricador (Fig. 3). Esta marca aunque es muy parecida a una citada en los dos repertorios antes nombrados no es exactamente igual. Blas la imprimió en libros como, Demostraciones que en celebridad del nacimiento de los dos infantes gemelos y ajuste definitivo de la paz con la nacion britanica hizo la ... ciudad de Zaragoza, de Tomas Sebastián y Latre. ${ }^{19}$

\footnotetext{
15 ARSEZ. Acta del 14/02/1783, tomo 9, pp. 27v - 28.

16 ADZ. Libro sacramental de la parroquia de La Magdalena, 1762 - 1813, tomo 6, p. 107.

17 ANZ. Testamento de Blas Miedes, Protocolo de Pedro García Navascués, 1786, signatura 5721, ff. 234v - 235v.

18 Para la investigación de las marcas tipográficas utilizadas por la familia Miedes hemos partido de dos obras fundamentales para el estudio de dichos grabados, la gran obra de Francisco VINDEL, Escudos y marcas de impresos y libreros en España durante los siglos XV a XIX (1485-1850), Barcelona, Orbis, 1942, básica para cualquier investigador de esta materia, y la obra de JiMÉNEZ CATALÁN, Ensayo de una tipografía..., en la que se menciona, aunque muy brevemente algunas de las marcas empleadas por los impresores.

19 Tomás Sebastián y Latre, Demostraciones que en celebridad del nacimiento de los dos infantes gemelos y ajuste definitivo de la paz, con la nacion britanica hizo la ... ciudad de Zaragoza, En Zaragoza, en la imprenta de Blas Miedes, [1784].
} 
El mismo año de 1784 Blas usó otra marca que es muy similar a la anterior (Fig. 4). En esta solamente aparece su apellido pero con la curiosa circunstancia de que lo divide en dos filas y utiliza de una forma muy correcta la ortografía al colocar un guion al separarlo en dos líneas y un punto al final del mismo. La onomástica está rodeada por un grabado ornamental como en la primera figura pero este adorno es diferente al anterior.

Esta marca no se incluye en ninguno de las dos fuentes mencionadas y la colocó en libros como Ensayo historico-apologetico de la literatura española contra las opiniones preocupadas de algunos escritores modernos italianos de Javier Lampillas. ${ }^{20}$

A partir de 1785 empleó un grabado formado por sus iniciales en lugar de su nombre completo si bien mantuvo el uso del elemento ornamental que rodea dichas letras. Compuso un sello con las letras de su apellido M. I. E. D. S. combinadas entre sí; este monograma fue una constante durante toda la vida del taller.

La primera marca en la que dispuso dicho elemento (Fig. 5) no aparece en los textos básicos ya mencionados y la imprimió en libros como Respuesta del señor abate don Xavier Lampillas a los cargos recopilados por el señor abate Tiraboschi en su carta al señor abate N. N. sobre el ensayo bistorico-apologetico de la literatura española. ${ }^{21}$

La última que utilizó Blas Miedes en su carrera laboral se compone únicamente de dichas iniciales pero sin ninguna orla rodeándolas. El único adorno que lleva es una raya en la parte inferior que destaca la marca (Fig. 6). Está situada en la portada de algunos de sus trabajos como por ejemplo: Ordinaciones de la muy ilustre y antiquísima Cofradia de Nuestra Señora del Olivary del Milagro, fundada en su hermita sita en la calle de Predicadores de la ciudad de Zaragoza.22

\section{Bruna Lloscos (1786-1792)}

A la muerte de su marido, Bruna Lloscos se puso al frente del negocio familiar para, de esta manera convertirse en una de las pocas mujeres impresoras de su época, pero como era costumbre en este período nunca firmó con su nombre sino como «viuda de Blas Miedes» manteniendo el nombre de su esposo y la denominación de un taller que ya había alcanzado fama y garantía de calidad.

\footnotetext{
20 Javier LAMPILLAS, Ensayo historico-apologetico de la literatura española contra las opiniones preocupadas de algunos escritores modernos italianos, En Zaragoza, en la oficina de Blas Miedes..., 1784.

${ }^{21}$ Javier LAMPILLAS, Respuesta del señor abate don Xavier Lampillas a los cargos recopilados por el señor abate Tiraboschi en su carta al señor abate N. N. sobre el ensayo bistorico-apologetico de la literatura española, En Zaragoza, en la oficina de Blas Miedes ..., 1786.

22 Cofradía de Nuestra Señora del Olivar y del Milagro (Zaragoza), Ordinaciones de la muy ilustre y antiquísima Cofradia de Nuestra Señora del Olivar y del Milagro, fundada en su hermita sita en la calle de Predicadores de la ciudad de Zaragoza, En Zarag., en la oficina de Blas Miedes ..., 1786.
}

Titivillus, ISSN 2387-0915, ISSN-e 2603-9966, 4 (2018), pp. 63-79 
El comienzo laboral de Bruna fue duro pero pese a ello consiguió asentar la economía familiar al lograr que la Real Sociedad la designara impresora de esta institución. al igual que había sucedido con su esposo. Para ello tuvo que competir con Antonio Heras y su hijo Medardo, quienes también requirieron ser sus impresores. Para asegurarse su puesto, Bruna entregó un memorial en el que alegaba tener «dos oficiales bien instruidos que desempeñaran la imprenta».23 Finalmente la Sociedad se decantó por la viuda de Blas, concediéndole los mismos términos y circunstancias que poseía en el pasado su difunto esposo.

La producción del taller siguió la misma trayectoria que la de su marido al imprimir textos para la Real Sociedad pero también libros con matices populares como el Manual de economía casera, ó elementos del gobierno de una casa, que en estilo familiar y acomodado à la capacidad de todos.24

Al igual que Blas, Bruna prolongó su compromiso con el Arzobispo de Zaragoza, Agustín de Lezo y Palomeque y entre su producción se hallan títulos como Constituciones y Reglas para el Real Seminario Sacerdotal de San Carlos de la ciudad de Zaragoza: y sus operarios y directores, 25 que el mismo Arzobispo redactó.

Murió el 6 de febrero de $1792^{26}$ a la edad de cincuenta años en la misma casa de la calle Gavín, sin llegar a hacer testamento.

Bruna solamente utilizó una marca tipográfica en su labor como impresora y fue la última que empleó su marido (Fig. 6).

\section{Mariano Miedes (1792-1831)}

Tras la muerte de Bruna, la producción impresa pasó a manos de su hijo Mariano, quien se encargó de tomar las riendas del negocio.

Poco tiempo después, en febrero de 1792 la Junta General de la Real Sociedad confirmó su nombramiento como impresor de dicha institución, manteniendo de esta manera el mismo contrato que sus progenitores. ${ }^{27}$

Desde el comienzo de su andadura, Mariano tuvo problemas relacionados con la tipografía de sus textos. A finales de noviembre de 1795, un acta de la

\footnotetext{
23 ARSEZ. Acta del 17/11/1786, tomo 12. En este documento no aparecen citados los nombres de los dos oficiales que formaban parte en este momento del taller de Bruna Lloscos, por lo que desconocemos su identidad.

${ }^{24}$ Felipe COSIO É ITUÑo, Manual de economía casera ó elementos del gobierno de una casa, que en estilo familiar y acomodado à la capacidad de todos, en Zaragoza, en la oficina de la Viuda de Blas Miedes, 1787.

25 Agustín de LeZo y PAlomeque, Constituciones y Reglas para el Real Seminario Sacerdotal de San Carlos de la ciudad de Zaragoza: y sus operarios y directores, en Zaragoza, oficina de la Viuda de Blas Miedes, 1787.

26 ADZ. Libro sacramental de la parroquia de La Magdalena, 1787 - 1792, tomo 11, p. 127.

27 ARSEZ. Acta del 17/02/1792, tomo 18, p. 18.
} 
Real Sociedad ${ }^{28}$ habla de la escasa calidad que empezaban a tener sus ejemplares ya que tras haber realizado la impresión de los carteles y esquelas de ese año, los socios decidieron alertarle de que si no cambiaba de tipo de letra sería reemplazado.

Este hecho fue una constante a lo largo de su vida laboral pero aun así, Mariano Miedes supo gestionar sus encargos convirtiéndose en uno de los impresores más prolíficos del siglo XIX.

Son abundantes sus textos sobre política, teatro o medicina pero también sobre religión y teología debido a que en 1806 ya ejercía como impresor del Cabildo Metropolitano de Zaragoza, cargo que no dudó en señalar en las páginas principales de composiciones como por ejemplo, Panegirico del santo niño y martir zaragozano Domingo de Val: que en la solemne festividad celebrada el 26 de agosto del año 1806 en el santo Templo Metropolitano del Salvador de Zaragoza.29

Existe también otro tipo de documentación salida de su taller como los bandos o los textos patrocinados por el concejo de Zaragoza, al ser este uno de sus clientes más importantes.

Sus logros no acabaron aquí, pues en 1810 consiguió que el Canal Imperial lo contratara para difundir sus avancen en torno a la construcción de este proyecto hidráulico. Estas dos instituciones junto a la Real Sociedad, supusieron el grueso de sus encargos, lo que le permitió gozar de estabilidad económica.

Mariano contrajo nupcias con Justa Laseca, quien murió en agosto de 1792 dejando testamento a favor de sus tres hijos: Miguela, Joaquina y Martín. ${ }^{30}$ Este documento ha desaparecido del Archivo del Colegio de Notarios de Aragón al igual que la mitad de los protocolos de dicho notario, por lo que desconocemos su contenido exacto. ${ }^{31}$

En 1822 Mariano Miedes ya había contraído segundas nupcias con Braulia Frasinete y tenían cuatro hijos: Ramón, Mariano, Concepción y Blasa. ${ }^{32}$

Un punto de inflexión en su carrera se dio en las últimas décadas de su vida. Por estas fechas, Mariano Miedes volvió a sufrir problemas laborales por el uso inadecuado de las fundiciones, pero en esta ocasión derivaron en graves pérdidas económicas.

En 1818 la Junta General de la Real Sociedad decidió temporalmente prescindir de sus servicios y contratar al impresor Andrés Sebastián para

\footnotetext{
28 ARSEZ. Acta del 9/01/1795, tomo 21, p. 4.

${ }^{29}$ Camilo Foncillas de SANTA Teresa, Panegirico del santo niño y martir zaragozano Domingo de Val: que en la solemne festividad celebrada el 26 de agosto del año 1806 en el santo Templo Metropolitano del Salvador de Zaragoza, en Zaragoza, en la oficina de Mariano Miedes, 1806.

30 ADZ. Libro sacramental de la parroquia de La Magdalena, 1762 - 1813, tomo 6, p. 183.

31 ANZ. Protocolo de Joaquín Lasala, 1807, signatura 53360.

32 ANZ. Testamento de Mariano Miedes, Protocolo de Pablo Fernández Treviño, 1822, signatura 5530, ff. $52-53 \mathrm{v}$.
}

Titivillus, ISSN 2387-0915, ISSN-e 2603-9966, 4 (2018), pp. 63-79 
realizar trabajos puntuales al poseer un repertorio más surtido de tipografía. ${ }^{33}$ Aún es más, para 1830 esta institución amonestó a Mariano por haber realizado una tirada de cincuenta libros, Egercicios públicos de matemáticas, con numerosas erratas que hacían que el texto fuera completamente ilegible. ${ }^{34}$

Frente a esta situación, los miembros de la Real Sociedad decidieron continuar con el pacto establecido, pues aunque el impresor había sido advertido anteriormente, se tuvo en cuenta sus credenciales. Siete días después, el taller de los Miedes había rectificado los ejemplares sufragando el coste añadido.

Finalmente, el 22 de febrero de 1831 falleció Mariano a la edad de 57 años en el $\mathrm{n}^{\circ} 6$ de la calle de Platería ${ }^{35}$ (Fig. 14). Su muerte fue inesperada ya que como dicen las fuentes, el difunto «recibio los Sacramentos de Penitencia y Viatico, no el de Extremaunción por no haber dado lugar su accidente».36

Mariano siguiendo la tradición familiar empleó hasta cinco marcas diferentes a lo largo de su carrera.

La primera que imprimió es una de las utilizadas por su padre, la compuesta por el monograma y la orla vegetal rodeándola (Fig. 5). La grabó en libros como Sermon de la purificacion de la Virgen N.tra S.ra que en el dia 2 de febrero de 1793 dixo ... ${ }^{37}$

En 1794 Mariano cambió su marca personal aunque mantuvo el monograma de los Miedes. En ella se observan elementos que no se habían utilizado previamente: dos ángeles flanqueando el sello familiar y un lema que dice «Omnia Vincit Labon» que se traduce como «el trabajo todo lo vence» (Fig. 7). La estampó en libros como De libris quibusdam hispanorum rarioribus disquisitio. ${ }^{38}$

La siguiente marca utilizada por Mariano fue el monograma de su taller pero sin la raya que lo enfatiza (Fig. 8). La imprimió en libros como Relacion de los experimentos de agricultura hechos en Zaragoza en el año de 1797 acerca del cultivo y rendimiento en pan de diferentes especies de trigo. ${ }^{39}$ Este grabado tampoco está descrito en ninguna de las fuentes anteriormente mencionadas.

33 ARSEZ. Acta del 18/09/1818, tomo 36, p. 470.

34 ARSEZ. Acta del 1/10/1830, tomo 38, pp. 151 y 152.

35 ANZ. Fe de muerte de Mariano Miedes, Protocolo de Pablo Fernández Treviño, 1831, signatura 5530, f. 50v. ACP. Partida de defunción, Libro sacramental de la parroquia del Pilar, tomo 10, p. 104.

36 ACP. Op. cit., 1831, tomo 10, p. 104.

37 Tomás de SAN José, Sermon de la purificacion de la Virgen N.tra S.ra que en el dia 2 de febrero de 1793 dixo ..., En Zaragoza, por Mariano Miedes, [ca. 1793].

38 Ignacio Jordán de ASSO Y DEL Río, De libris quibusdam hispanorum rarioribus disquisitio, Caesaraugustae, ex Typographia Mariani Miedes, 1794.

39 Ignacio Jordán de ASSO Y DEL RíO, Relacion de los experimentos de agricultura bechos en Zaragoza en el año de 1797 acerca del cultivo y rendimiento en pan de diferentes especies de trigo [Zaragoza], en la imprenta de Mariano Miedes, [1797?]. 
Asimismo Mariano empleó la marca del blasón con la línea que la destaca que tanto su padre como su madre utilizaron (Fig. 6).

La última marca de Mariano se compone de las iniciales de la familia rodeadas por un sencillo adorno vegetal rematado por una corona (Fig. 9). La insertó en libros como Milagro asombroso, portento singularisimo obrado por la intercesion de Maria Santisima del Pilar de Zaragoza en la restitucion de una pierna a Miguel Juan Pellicer... ${ }^{40}$ Esta marca no se encuentra mencionada en ninguno de los textos consultados.

\section{Braulia Frasinete (1831-ca. 1835)}

Sin el cabeza de familia, el taller continuó en activo al pasar a manos de Braulia Frasinete, segunda esposa de Mariano. Su trayectoria laboral fue muy breve y casi todo el grueso de su trabajo tuvo una temática religiosa aunque destacan algunas obras profanas como Fábulas mitológicas: útiles para la primera enseñanza de la juventud en las escuelas, y necesarias á los que han de profesar con perfeccion las bellas artes. ${ }^{41}$

Tan solo tres días después de la muerte de su esposo, requirió ocupar el cargo de impresora de la Real Sociedad pero en este caso, el Comité General acordó que debía de presentar un repertorio de los caracteres que poseía la imprenta para evitar que se repitieran los problemas del pasado. ${ }^{42}$

Una semana después, Braulia formuló un recurso para poder ejercer de impresora de la sociedad, pero esta vez con el apoyo de su cuñado Francisco Magallón quien se comprometió a asumir toda la responsabilidad del taller pero siempre bajo la firma de la viuda de Mariano. ${ }^{43}$ Finalmente, la resolución de la institución fue favorable.

Por desgracia el fondo del Archivo de la Real Sociedad no ha conservado el muestrario del taller de los Miedes. Pese a ello, podemos hacernos una idea de cómo eran las fundiciones empleadas ya que estas no habían variado demasiado, pues nuevamente en febrero de 1831 surgieron las mismas erratas.

En ese momento Braulia Frasinete no pudo hacer frente a un pedido de quinientos ejemplares por lo que la Real Sociedad decidió concederle el encargo a Cristóbal Magallón, su sobrino. ${ }^{44}$

\footnotetext{
40 Eusebio XIMENEZ, Milagro asombroso, portento singularisimo obrado por la intercesion de Maria Santisima del Pilar de Zaragoza en la restitucion de una pierna a Miguel Juan Pellicer ..., Zaragoza, en la oficina de Mariano Mieldes, 1808.

${ }^{41}$ Manuel Fermín de CIDÓN É ITURRALDE, Fábulas mitológicas: útiles para la primera enseñanza de la juventud en las escuelas, y necesarias á los que han de profesar con perfeccion las bellas artes..., en Zaragoza, en la imprenta de la Viuda Mariano Miedes, 1832.

42 ARSEZ. Acta del 25/02/1831, tomo 38, pp. 279 y 280.

43 ARSEZ. Acta del 4/03/1831, tomo 38, p. 283.

44 ARSEZ. Acta del 21/02/1834, tomo 38, p. 430.
}

Titivillus, ISSN 2387-0915, ISSN-e 2603-9966, 4 (2018), pp. 63-79 
Es posible que la viuda de Mariano Miedes invirtiera algo de capital en la imprenta como así lo muestran los impresos de 1835. En ellos nos encontramos portadas creadas con un repertorio tipográfico muy variado, lo que supone un verdadero alarde visual. Un ejemplo es Alegación en derecho por el Cabildo metropolitano de Zaragoza en el Juicio de inventario de muebles, frutos, dinero y papeles executado á instancia de D. Juan Maritoreni. 45 (Fig. 2)

A partir de 1835, la actividad de Braulia Frasinete decayó hasta desaparecer por completo a finales de los años $30 .{ }^{46}$

Braulia al contrario que el resto de la familia no usó ninguna marca tipográfica en sus trabajos como impresora.

Todos los miembros de la familia Miedes, como hemos dicho, trabajaron para la Real Sociedad y en los libros que imprimieron para ella grabaron el escudo de esta institución: la conocida imagen del Árbol de Sobrarbe y el lema «Florece fomentando» (Fig. 11). Mariano fue el único que usó otra versión de este emblema (Fig. 12) sin duda más moderno y elaborado que el anterior, pero sigue haciendo honor al nuevo siglo en el que fue impreso.

\section{Conclusiones}

Con este artículo ha quedado plasmada la historia completa del taller de imprenta perteneciente a la familia Miedes a lo largo de más de medio siglo y se han puesto en valor dos figuras femeninas, Bruna Lloscos y Braulia Frasinete, que hasta este momento eran conocidas con el apelativo de «viuda de» dándoles la relevancia que se merecen.

Ha sido posible la acotación cronológica de las trayectorias laborales de todos los miembros que formaron parte de la imprenta familiar. Esto se debe a la unión de dos vías de trabajo, por una parte el análisis de los impresos y por otra, el cotejo de información procedente de diversos archivos zaragozanos.

En cuanto a la investigación de las marcas tipográficas usadas por la familia se han podido establecer cinco marcas no catalogadas por ninguna de las investigaciones realizadas hasta la fecha, así como una marca (Fig. 10) que aunque mencionada por Vindel no ha sido posible encontrarla en ninguno de

45 Alegación en derecho por el Cabildo metropolitano de Zaragoza en el Juicio de inventario de muebles, frutos, dinero y papeles executado á instancia de D. Juan Maritoreni pendiente de grado de vista ante esta Real Audiencia ... piden al cablido la entrega y adjudicación de frutos, en Zaragoza, imprenta de la Viuda de Mariano Miedes, 1835.

${ }^{46}$ La Gran Enciclopedia Aragonesa propone 1837 como el momento en el que cesó el trabajo de los Miedes debido a que la imprenta fue adquirida por Melchor Gallifa. Tras cotejar la documentación depositada en el Archivo del Colegio Notarial de Aragón, los libros sacramentales de la parroquia del Pilar y el Archivo de la Real Sociedad, no hemos podido encontrar ningún texto que demuestre esta idea. GRAN ENCICLOPEDIA Aragonesa, voz Mariano Miedes y voz Melchor Gallifa, <http://www.enciclopediaaragonesa.com/>, [Consulta: 8 octubre de 2017]. 
los impresos por él citados, quizás debido a la desaparición de los libros en los que aparecía.

En definitiva, con esta investigación los Miedes han recobrado la importancia que poseían en los siglos XVIII y XIX al ser grandes trabajadores que fueron patrocinados por figuras importantes del panorama aragonés como el Canal Imperial, el Arzobispado, el Ayuntamiento de Zaragoza y la Real Sociedad Económica Aragonesa de Amigos del País.

Se han aportado datos desconocidos pero aún quedan temas que necesitan una respuesta como la supuesta venta de la imprenta a Melchor Gallifa, que esperamos completar en futuras investigaciones. 
Figuras

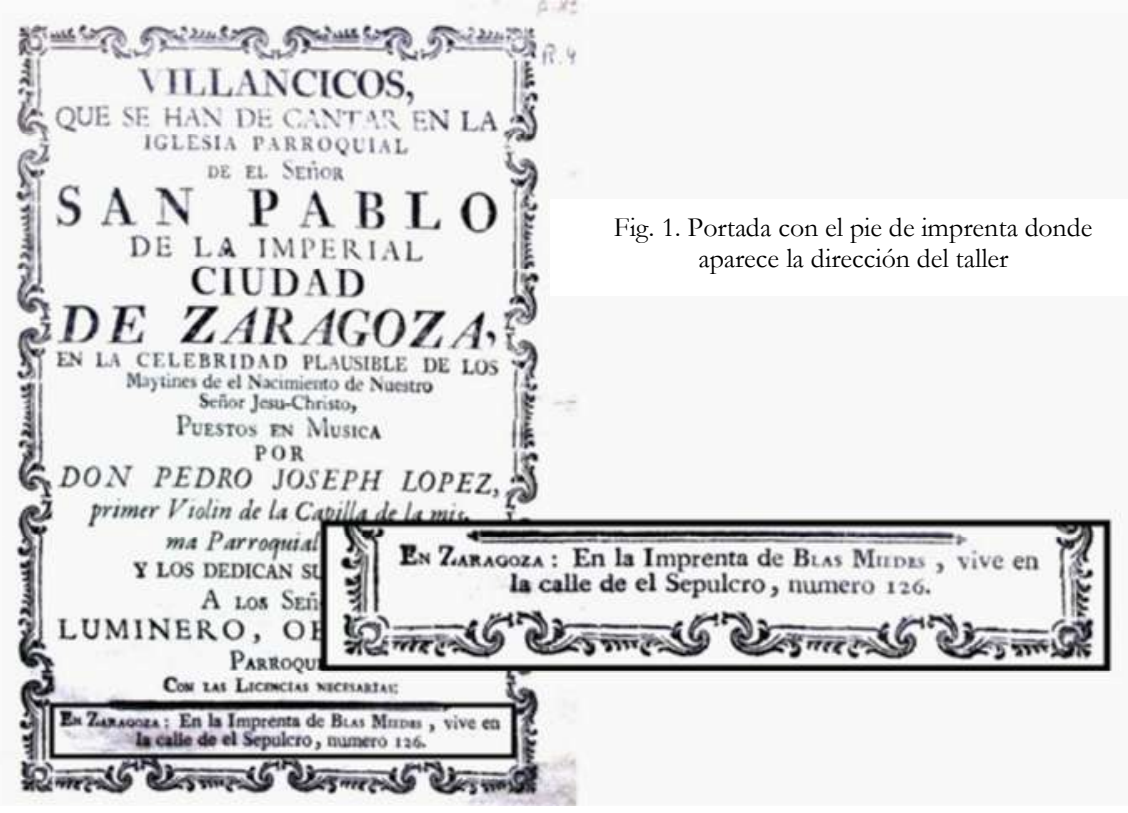

Fig. 2. Portada creada con diferentes fuentes tipográficas

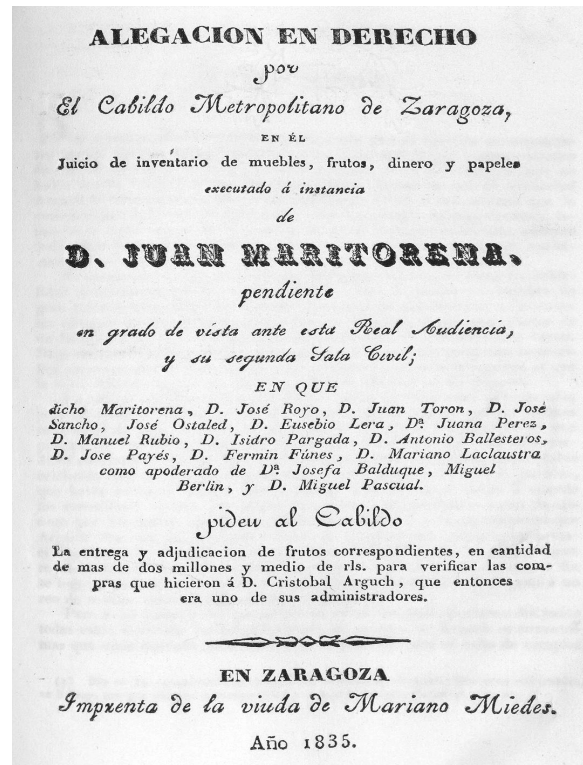

Titivillus, ISSN 2387-0915, ISSN-e 2603-9966, 4 (2018), pp. 63-79 


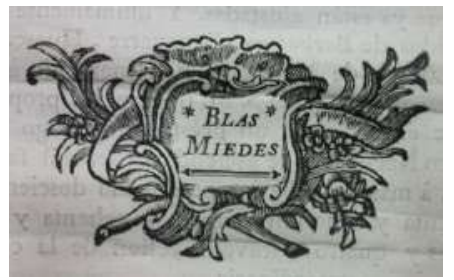

Fig. 3. Marca ${ }^{\circ} 1$ de Blas Miedes Marca no catalogada

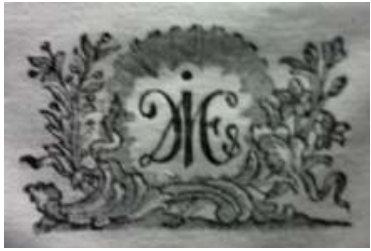

Fig. 5. Marca usada por Blas y por Mariano Marca no catalogada

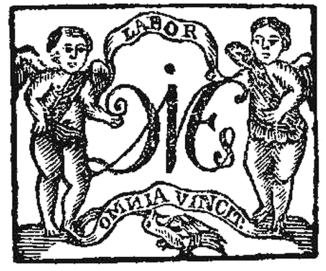

Fig. 7. Marca usada por Mariano

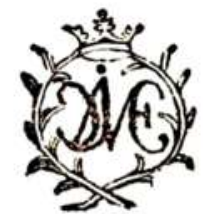

Fig. 9. Marca usada por Mariano Marca no catalogada

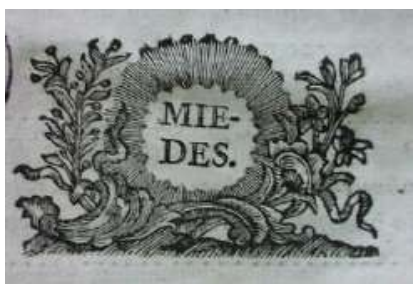

Fig. 4. Marca ${ }^{\circ} 2$ de Blas Miedes Marca no catalogada

\section{Dics}

Fig. 6. Marca usada por Blas y por Bruna

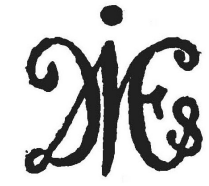

Fig. 8. Marca usada por Mariano Marca no catalogada

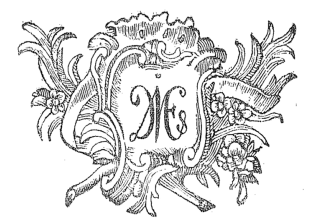

Fig. 10. Marca descrita por Vindel y no localizada 


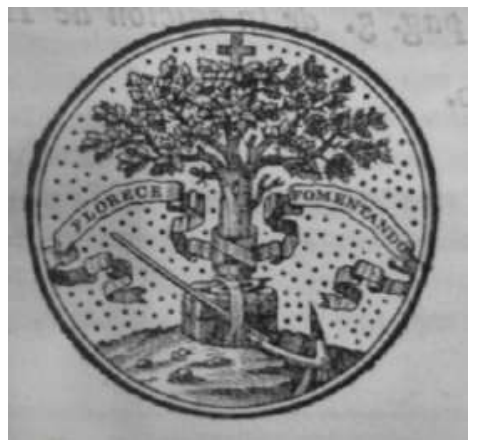

Fig. 11. Marca de la Real Sociedad usada por todos los miembros de la familia Miedes

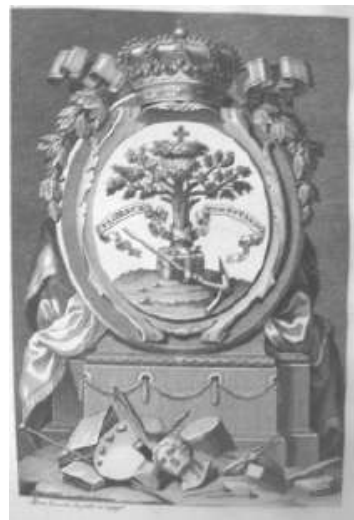

Fig. 12. Marca de la Real Sociedad usada solo por Mariano Miedes
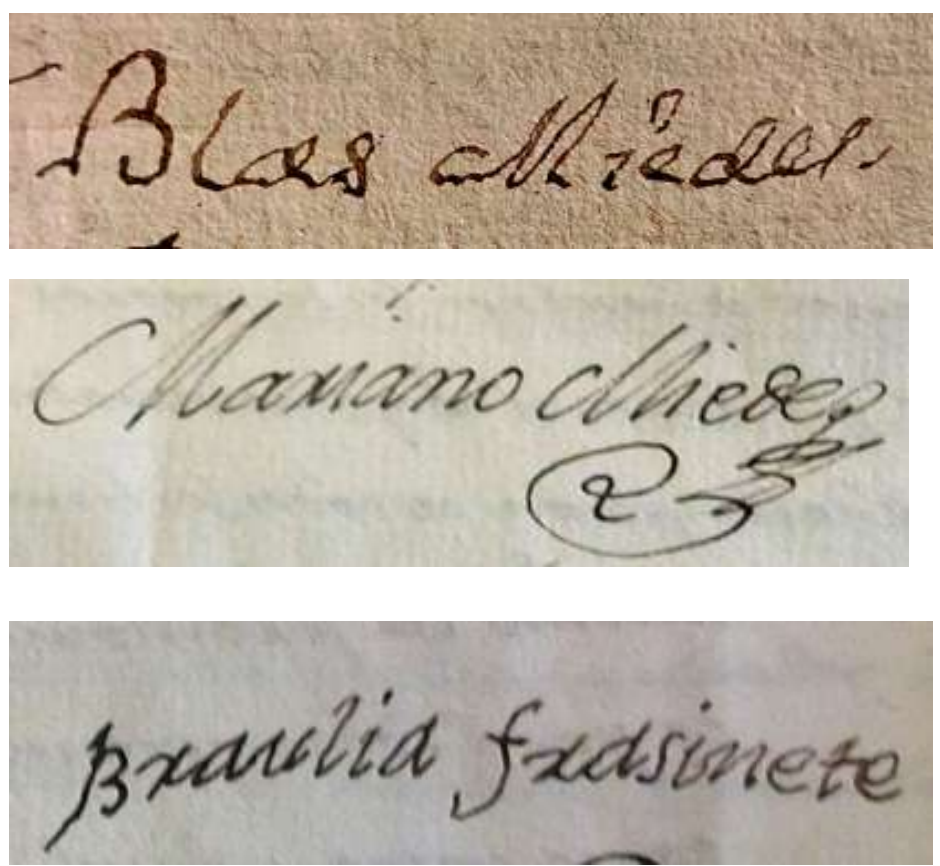

Fig. 13. Firmas de Blas Miedes, Mariano Miedes y Braulia Frasinete..$^{47}$ Por el contrario, la rúbrica de Bruna Lloscos no aparece junto a estas porque tal como ella aseguró, no sabía escribir ${ }^{48}$

${ }^{47}$ Firmas extraídas de sus testamentos ANZ. Testamento de Blas Miedes, op. cit., f. 235v; y Testamento de Mariano Miedes, op. cit. f. 53v.

Titivillus, ISSN 2387-0915, ISSN-e 2603-9966, 4 (2018), pp. 63-79 


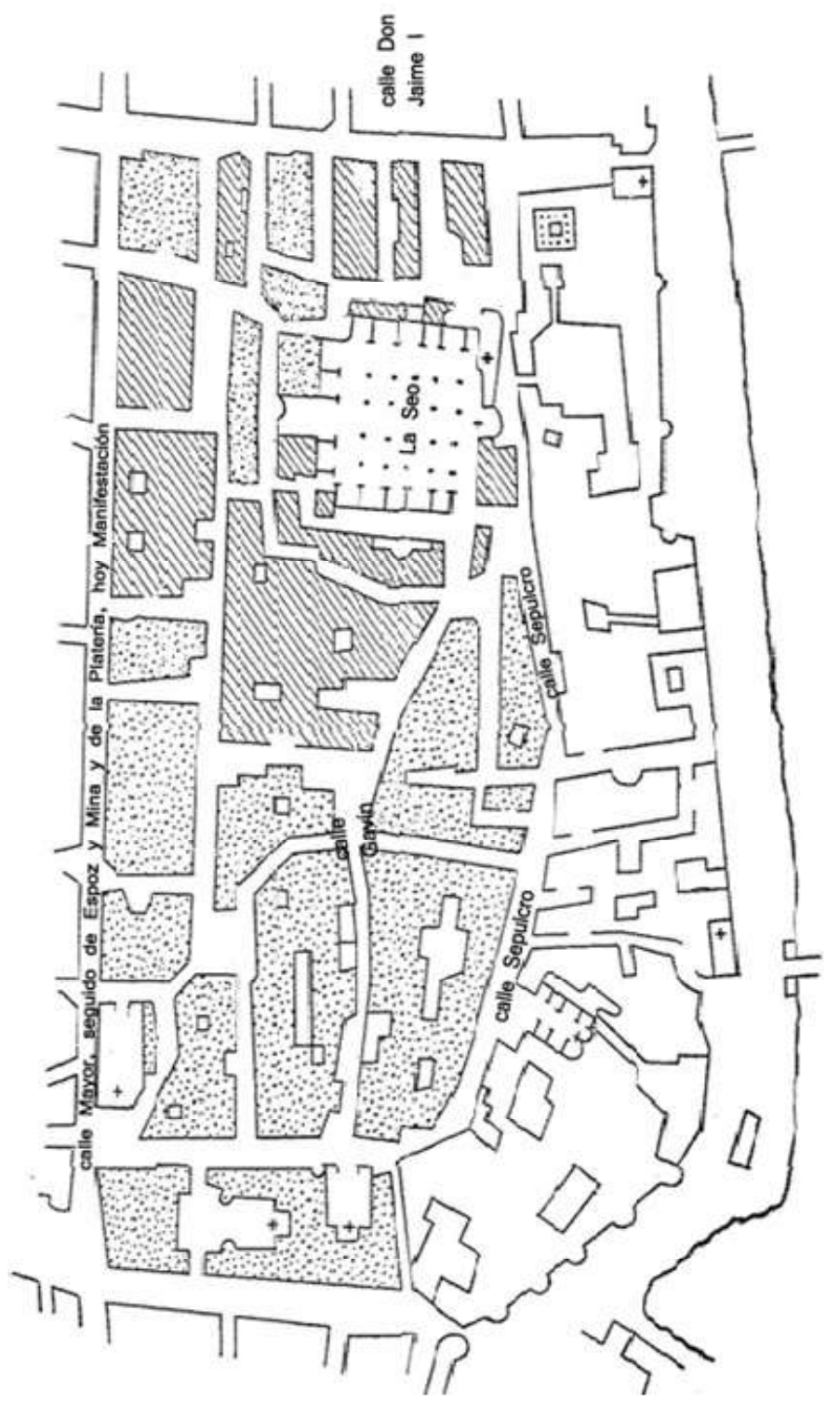

Fig. 14. Plano del Barrio de la Seo a finales del siglo XVIII ${ }^{49}$

48 ANZ. Protocolo de Pascual de Almerge, 1787, signatura 5343, f. 76v.

49 Fuente: Ángel CANellas LóPEZ, Nota histórica sobre el barrio zaragozano de La Seo, Zaragoza, Institución Fernando el Católico, 1980.

Titivillus, ISSN 2387-0915, ISSN-e 2603-9966, 4 (2018), pp. 63-79 


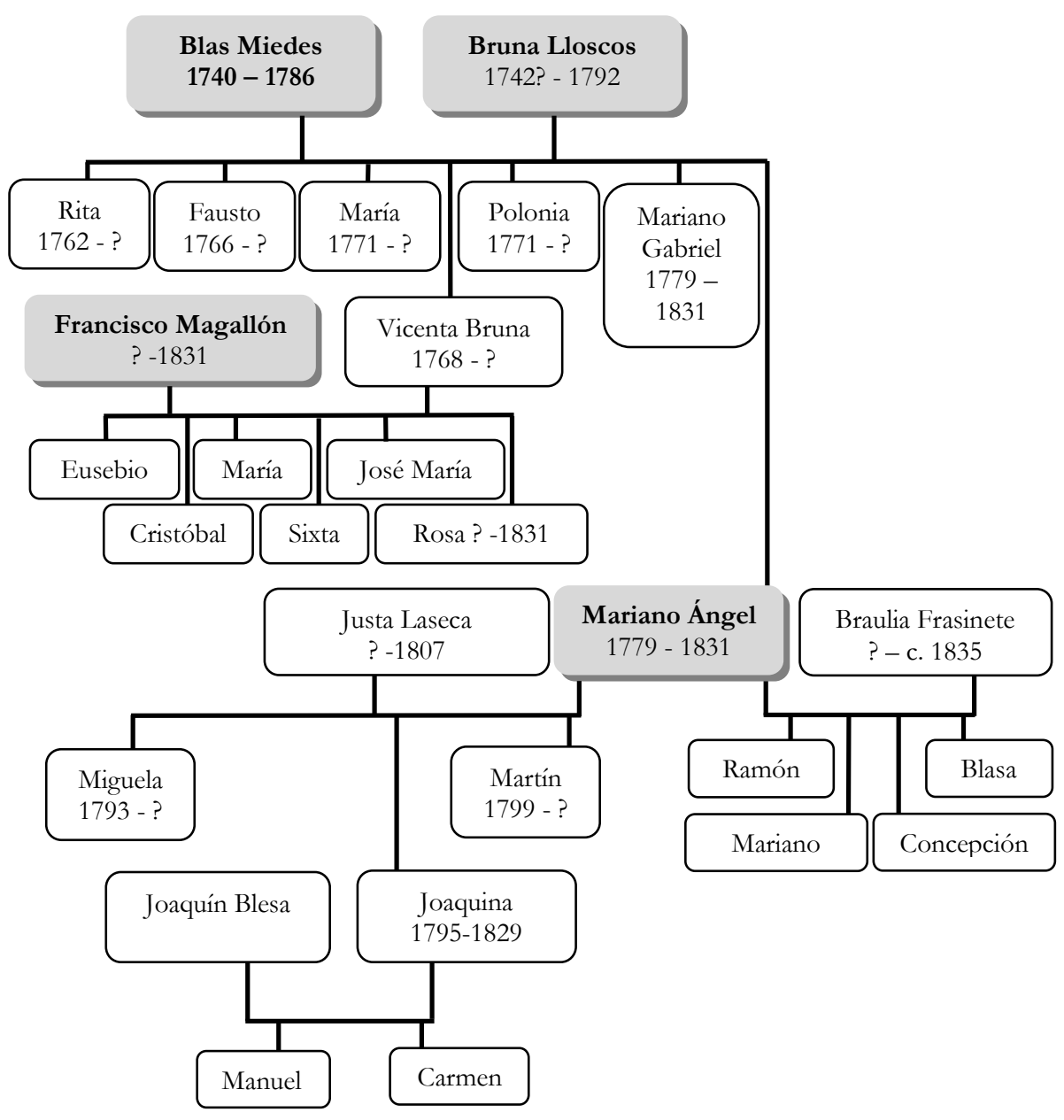

Fig. 15. Árbol genealógico de la familia Miedes 
